\title{
RESENHA DE ESCRITOS JUDAICOS DE HANNAH ARENDT
}

\author{
Laura Degaspare Monte Mascaro ${ }^{1}$ \\ Luciana Garcia de Oliveira \\ Thiago Dias da Silva ${ }^{3}$
}

Como é comum entre grandes autores, Hannah Arendt deixou em sua gaveta inúmeros textos não publicados. Produzidos em várias ocasiões e para diversos fins, estes textos formam uma enorme massa de escritos que versam sobre muitos temas e que, há já algumas décadas, têm sido editados e publicados na Alemanha e nos Estados Unidos na forma de coletânea de textos. Escritos judaicos ${ }^{4}$ é a tradução para o português de The Jewish Writings, ${ }^{5}$ coletânea lançada em 2007 por Jerome Kohn e Ron H. Feldman. O volume traz a quase totalidade dos textos publicados anteriormente em The Jew as Pariah — lançada em 1978, não traduzida para o português e há muito esgotada - e uma série de outros textos. A tradução para o português ficou a nosso cargo e representa um trabalho feito no âmbito do Centro de Estudos Hannah Arendt, coordenado pela Professora Cláudia Perrone-Moisés, da Faculdade de Direito da USP. Produzidos em estreito vínculo com o momento na vida de Arendt, os textos da coletânea foram originalmente escritos em inglês, francês ou alemão e, embora a base desta edição brasileira tenha sido a edição americana, os tradutores recorreram aos originais sempre que a eles tiveram acesso, o que foi o caso dos três textos originalmente escritos em francês e de vários redigidos em alemão.

Escritos judaicos é talvez a maior das coletâneas de textos de Hannah Arendt publicada até então — rivalizada apenas por Compreender - e cobre um longo período da vida da autora: de 1932 a 1966. Como o título já indica, os escritos giram em torno da questão e da condição judaicas e dos problemas a elas vinculados nos tempos modernos, em especial o século XX. A organização cronológica do volume, separado por décadas, torna conspícuo o desenrolar

\footnotetext{
${ }^{1}$ Doutoranda em literatura francesa na FFLCH-USP e coordenadora do Centro de Estudos Hannah Arendt. 2 Mestranda do programa de estudos árabes e judaicos da FFLCH-USP e pesquisadora do Centro de Estudos Hannah Arendt.

${ }^{3}$ Doutorando em filosofia na FFLCH-USP e pesquisador do Centro de Estudos Hannah Arendt.

4 ARENDT, H - Escritos judaicos [Tradução de Laura Degaspare Monte Mascaro, Luciana Garcia de Oliveira e Thiago Dias da Silva]. Barueri, SP: Amarylis, 2016. 895 páginas

5 ARENDT, H - The Jewish Writings. New York: Schocken Books, 2007.
} 
do pensamento arendtiano sobre o tema em estreita proximidade com as histórias do século XX e da própria autora. A própria mudança dos assuntos ao longo da coletânea apresenta já um panorama das questões que envolveram os judeus e também o percurso da jovem intelectual judia e alemã que se viu forçada a pensar seu lugar na Alemanha dos anos 1930, que se viu obrigada a emigrar para a França e depois para os Estados Unidos, que assistiu com aflição à construção do estado de Israel e ao crescimento das tensões entre judeus e árabes na Palestina, que finalmente sofreu um duro ostracismo da comunidade judaica em reação a seu livro sobre o julgamento de Adolf Eichmann.

\section{A Questão judaica $(\operatorname{anos} 30)$}

Os primeiros textos arendtianos aqui presentes foram escritos na Alemanha e na França ao longo da década de 1930 e, refletindo os tempos sombrios, formam uma longa reflexão a respeito do lugar dos judeus na Europa. Como não poderia deixar de ser, Arendt aborda este problema servindo-se das ideias dos grandes autores significativos para a questão, como Herder, Mendelssohn e Lessing. A indisfarçada admiração por estes dois últimos acompanha a descrição das diferentes posições que o pensamento iluminista adotou relativamente à tensão causada entre as demandas de igualdade típicas do iluminismo e as dificuldades de assimilação dos judeus, oriundos de tradição tão distinta e fisicamente tão próximos (Cf. "O Iluminismo e a questão judaica”). Também como em outros escritos, Arendt recorre aqui bastante a fatos históricos, mais especificamente aos que marcaram as tensas relações entre judeus e os demais europeus ao longo da modernidade; daí a grande presença de pogrons, situações de privilégios, de preconceito, inveja de riqueza, proximidade com o poder, usura e tantos outros (Cf. "Antissemitismo"). O leitor já familiarizado com a obra de Arendt não deixará de notar aqui a proximidade entre estes textos e certas passagens de Origens do totalitarismo e da biografia que Arendt dedicou a Rahel Varnhagen. O que talvez apareça como novidade ao leitor é a preocupação de Arendt com certos problemas mais diretamente concretos, cotidianos mesmo, como a formação profissional de jovens judeus (Cf. "A reclassificação profissional da juventude"), o papel das escolas judaicas na vida de crianças judias (Cf. “Contra círculos privados”), o papel das Aliyah (Cf. “Jovens vão embora para casa”).

\section{A Questão Palestina (anos 40-50)}

Ao longo da década de 1940, já nos Estados Unidos, Hannah Arendt torna-se uma militante pela paz no Oriente Médio. Em 1948 manifestou-se publicamente ante a presença de Menachem Begin, líder do "Partido Liberdade" (Thuat Haherut), classificado por ela como uma "organização terrorista, chauvinista e de direita da Palestina" ("Novo partido palestino", 
p. 691). Arendt relembra o evento conhecido como o massacre de Deir Yassin, um vilarejo árabe pacífico que foi impiedosamente cercado por bandos de terroristas liderados por Begin naquele mesmo ano, quando eclodiu o conflito Israel-Palestina.

Para a autora, a presença de Menachem Begin nos Estados Unidos, justamente em 1948, visava acima de tudo angariar apoio americano ao seu partido político para as próximas eleições israelenses e, da mesma forma, promover na grande comunidade judaica americana o programa político de Begin para a Palestina, baseado "em uma mistura de ultranacionalismo, misticismo religioso e superioridade racial" ("Novo partido palestino", p.693). A negação de um modelo exclusivista israelense é afirmado em "Paz ou armistício no Oriente Médio?”, no instante em que defende a paz como resultado direto de negociações e de um compromisso mútuo entre árabes e judeus. Nesse passo, opõe-se veementemente à implementação de uma supremacia política e cultural de modo a ignorar o despertar dos povos coloniais.

O fracasso da coexistência pacífica entre árabes e judeus deveu-se à formação de uma estrutura econômica regional de forma isolada, salvo algumas poucas exceções como certas organizações exportadoras árabes e judaicas e algumas poucas fábricas na Palestina que empregava mão de obra árabe e judia. Hannah Arendt ainda lembra algumas iniciativas de acordos entre minorias árabes e judaicas que ambos os lados permitiram que caíssem no esquecimento, como a reunião de líderes sionistas e árabes em Damaso em 1913, o famoso Tratado de Amizade de 1919 entre o rei Faizal da Síria e Chaim Weizmann e a Conferência entre árabes e judeus em 1922 no Cairo. Arendt reitera que a construção da pátria judaica nunca dependeu da cooperação com os árabes, ao contrário, foi demasiadamente priorizado o "espírito pioneiro da mão de obra judaica e do apoio financeiro da comunidade judaica mundial" ('Paz ou armistício no Oriente Médio?" p.710). A ideologia sionista não considerou a realidade na Palestina, atentou-se apenas para a apatridia judaica, com a transmissão inconsequente da ideia de "uma terra sem povo para um povo sem terra", sem considerar a população nativa da Palestina. O resultado imediato da guerra instalada na região foi o deslocamento de mais de 500 mil árabes dos territórios dominados por Israel e a dominação de um povo sobre o outro. A transferência de população aliada à recusa de Israel em readmitir os refugiados ao seu antigo lar, transformou o Estado judaico em uma entidade absolutamente negativa e conduziu Israel a um processo de balcanização. Ainda, toda a região tornou-se um campo de batalhas de interesses das grandes potências econômicas.

Um dos principais incômodos que acometem os estudiosos de Hannah Arendt, principalmente aqueles preocupados com o mundo e com a política: a natureza problematizadora, porém pouco propositiva de seus textos. Arendt refere-se ao sentido da política como sendo a liberdade, problematiza a possibilidade de conciliar as necessidades econômicas dos cidadãos com esse sentido; realiza uma crítica pungente do Estado-nação, cuja crise iniciara-se praticamente de maneira concomitante a seu surgimento, mas nunca, ou 
quase nunca, aponta uma saída palpável e concreta. Ela aponta apenas para a direção da busca por um sistema político que funcione de forma a promover o sentido da política, sendo que os resultados materiais decorreriam da própria ação humana orientada pela liberdade.

Os textos desta coletânea escritos a partir do final da década de 1930 refletem, no entanto, o engajamento da autora com a questão Palestina e com a promoção da paz no Oriente Médio. Neles, o leitor encontra propostas concretas a respeito da estrutura de um novo Estado na Palestina. Arendt via como a única alternativa à balcanização, a proposta de uma federação regional que compreendesse um Estado binacional árabe-judeu, que não seguiria o modelo do Estado-nação europeu e em que árabes e judeus dividiriam governos autônomos locais por meio de conselhos mistos de judeus e árabes. A fonte do poder desse Estado seria a população comum de judeus e árabes convivendo em vizinhança, que se reuniriam para lidar com seus problemas cotidianos, e suas decisões ascenderiam em diversos níveis de conselhos. Entretanto, a realização desse modelo demandaria sacrifícios e muita habilidade, sobretudo por parte dos pioneiros judeus, em reassentar os deslocados árabes para dentro do Estado. Sem cooperação mútua, a autora alerta para o perigo da sobrevivência nacional.

Arendt trataria mais tarde, em Sobre a Revolução, de um sistema de conselhos como uma estrutura que teria surgido espontaneamente em diversos contextos revolucionários dos séculos XIX e XX no mundo, mas que teria sido negligenciado pelos próprios dirigentes revolucionários, que os viam como órgãos passageiros na luta revolucionária pela libertação, mas que não poderiam se consolidar como uma forma de governo. No entanto, o tom ali adotado pela autora não é propositivo, mas sim analítico - mesmo porque ela acreditava que qualquer forma de governo só seria politicamente legítima na medida em que surgisse espontaneamente em um determinado contexto, a partir dos próprios agentes, não podendo ser algo idealizado a priori, externamente, sob o risco de se tornar uma imposição de "revolucionários profissionais" que não requeresse ação política, mas apenas execução.

No entanto, no caso do Estado Palestino, o tom propositivo era adequado porque Arendt o adotava enquanto agente política, envolvida diretamente na reconstrução da Palestina pelo menos desde a década de 1930, quando trabalhou para organizações como Youth Aliyah, dedicada ao auxílio a refugiados judeus que pretendiam emigrar para a Palestina. Em dezembro de 1948, ela escreve que "a independência da Palestina pode ser alcançada somente sobre uma sólida base de cooperação judaico-árabe" e "[O] autogoverno local e conselhos municipais e rurais mistos de judeus e árabes, em uma pequena escala e tão numerosos quanto possível, são as únicas medidas políticas realistas que eventualmente podem conduzir à emancipação política da Palestina. Ainda não é tarde demais" "“Para salvar a pátria judaica", p. 670).

Arendt lutou pela efetivação do Estado federado binacional ao lado de Judah Magnes e outros, embora sua proposta fosse ainda mais longe para que conseguisse abarcar a resolução de conflitos internos entre as etnias. No entanto, sua grande esperança não se 
concretizou, tendo vingado a proposta do Commonwealth judaico, o que possivelmente tenha acarretado a substancial diminuição de sua produção sobre assuntos judaicos a partir de 1950.

Embora suas esperanças não tenham se concretizado, podemos dizer que algumas de suas mais alarmantes previsões para o Estado Judaico demonstraram a capacidade de Arendt de olhar para o futuro a partir dos elementos presentes que começavam a se cristalizar, o que ela mesma reputava impossível, até mesmo para um olhar compreensivo. Em 1944, Arendt escreve o seguinte (“Sionismo Reconsiderado” pp. 632 e 594):

Se uma commonwealth judaica for obtida em um futuro próximo (...) terá sido devido à influência dos judeus americanos. (...) Mas se a commonwealth for proclamada contra a vontade dos árabes e sem o apoio dos povos mediterrâneos, serão necessários por muito tempo não apenas a ajuda financeira, como também o apoio político. (...) Isso pode se tornar eventualmente muito mais uma responsabilidade do que hoje se imagina (...).

(...) $[\mathrm{O}] \mathrm{s}$ sionistas, se continuarem a ignorar os povos do mediterrâneo e atenderem atentarem apenas para as grandes potências, parecerão ser apenas seus instrumentos, os agentes de interesses estrangeiros e hostis. Judeus que conhecem sua própria história devem ter consciência de que esse estado de coisas conduzirá inevitavelmente a uma nova onda de ódio aos judeus; o antissemitismo de amanhã afirmará que os judeus não só se aproveitaram da presença de grandes potências estrangeiras naquela região como também na verdade a haviam tramado (...)"

Ela chega a prever em 1948 ("Para Salvar a Pátria Judaica”) que os judeus que saíssem vitoriosos da guerra árabe-israelense viveriam cercados por uma população árabe hostil, isolados dentro de fronteiras permanentemente ameaçadas, absorvidos pelos esforços de autodefesa que passariam a pautar todos os seus outros interesses e atividades, comparando a futura Israel à Esparta.

\section{O Caso Eichmann (anos 1960)}

A última seção do livro é basicamente dedicada à feroz controvérsia que envolveu Eichmann em Jerusalém, publicado por Arendt no início dos anos 1960. Respondendo em carta a acusação de Gershom Scholem, para quem Arendt não tinha "amor pelo povo judeu" (Ahabath Israel), ela se afirma como uma intelectual equidistante, não movida pelo amor a um povo ou a um movimento, recusando-se a renunciar a condição judaica e, ao mesmo tempo, dizendo que "em toda minha vida, eu jamais 'amei' um povo ou coletividade - nem o povo 
alemão, nem o povo francês, nem o povo americano, nem a classe trabalhadora ou qualquer coisa desse tipo. Eu amo realmente 'apenas' meus amigos e o único tipo de amor que eu conheço e em que eu acredito é o amor por pessoas" (“A controvérsia Eichmann”, p. 757).

Em pelo menos dois momentos ("Respostas às perguntas de Samuel Grafton" e "O caso Eichmann e os alemães”), Arendt se esforça para esclarecer o polêmico e até hoje muito mal compreendido termo "banalidade do mal", um dos principais eixos em torno dos quais toda a controvérsia girou e ainda gira. A problemática em torno da parcialidade do promotor Hausner, cuja atuação no julgamento de Eichmann foi questionada por Arendt em seu relato do julgamento, também é retomada aqui. Nos textos aqui publicados, Arendt tem a chance de esclarecer sua posição a respeito da espinhosa questão da atuação dos conselhos judaicos ao longo do domínio nazista, um problema que adquiriu proporções para além da razoabilidade ao longo da controvérsia. Ela não intencionava tal desdobramento e afirma categoricamente que não houve ocasião para que os líderes lutassem contra tudo aquilo, embora ela esboce o que teria significado uma não cooperação dos conselhos com os alemães. Por fim, defendendo-se de ataques pessoais direcionados a ela, Arendt se dedica ainda a indicar os interesses precisos que regiam muitas das ações de seus acusadores ao longo controvérsia (Cf. "O formidável Dr. Robinson”).

Pare encerrar esta longa e turbulenta coletânea, os editores adicionaram como posfácio um belo texto escrito em tom carinhoso e familiar por Edna Brocke, sobrinha da "Grande Hannah". Uma maneira singela e elegante de concluir esta edição que vem contribuir para a ampliação do acesso do público lusófono ao pensamento de Hannah Arendt. 